\title{
Habitat of pre-hibernating larvae of the endangered butterfly Euphydryas aurinia (Lepidoptera: Nymphalidae): What can be learned from vegetation composition and architecture?
}

\author{
MARTin KONVICKA ${ }^{1,2^{*}}$, Vladimir HULA ${ }^{3}$ and ZDENEK FRIC ${ }^{1,2}$ \\ ${ }^{1}$ Department of Ecology and Conservation Biology, Institute of Entomology, Czech Academy of Sciences, Branišovská 31, \\ CZ-37005 Ceské Budějovice, Czech Republic \\ ${ }^{2}$ Department of Zoology, School of Biological Sciences, University of South Bohemia, Branišovská 31, 37005 České Budějovice, \\ Czech Republic \\ ${ }^{3}$ Department of Zoology, School of Agriculture, Mendel University, Zemědělská 1, Brno, Czech Republic
}

Key words. Melitaeini, butterfly conservation, Succisa pratensis, grassland vegetation, habitat quality, ordination, larval distribution

\begin{abstract}
Habitats of pre-hibernating gregarious larvae of the endangered Marsh Fritillary butterfly (Euphydryas aurinia) were studied in field in Western Bohemia, Czech Republic. The species inhabits moist seminatural meadows managed by light grazing and haymaking; the only local host plant is Succisa pratensis. The redundancy analyses of the vegetation composition (around 166 nest-bearing and 381 unoccupied host plants) showed that nest presence was positively associated with short cushion-forming grasses (esp. Nardus stricta). It was negatively associated with competitively superior tall grasses (e.g., Deschampsia caespitosa) and tall herbs. Comparison of Ellenberg's indicator values of vegetation in occupied vs. unoccupied plots revealed that the nests were more often found in drier, nitrogen-poorer and more acidic conditions than unoccupied plants. Multiple regressions of nest presence against architecture of the host plants (170 occupied, 1280 unoccupied) revealed that the nests were associated with densely clumped host plants, low to medium height of sward and mechanical disturbance. The patterns agree with our knowledge of the biology of the larvae: short sward (related to low nitrogen, humidity, and low $\mathrm{pH}$ ) facilitates larval basking; high host density reduces the likelihood of starvation. Sod disturbance facilitates host plant germination. The conditions favourable for the nests were also favourable for the host plant, but the plants grew in broader range of conditions than that occupied by the nests. The abandoning of a site results into a situation when the conditions first become intolerable for the butterfly, and ultimately for the plant. Since grazing and mowing have a different impact on vegetation composition and architecture, we propose that the studied populations have persisted in a semi-dynamic state in the two modes of management. Conservation management should mimic the dynamics of traditional land use on the smaller scales of extant colonies.
\end{abstract}

\section{INTRODUCTION}

Butterflies are among the best known and at the same time the most threatened group of temperate insects (Van Swaay \& Warren, 1999). Among them, the checkerspots of the tribe Melitaeini occupy an especially prominent position as one of the most intensively studied model systems in ecology and conservation (e.g., Ehrlich et al., 1975; Murphy \& Weiss, 1988; Hanski, 1999). It is known that individual species exhibit more exacting habitat requirements than would be predicted from the distribution of their host plants. The selectivity is typically attributable to the specific needs of the developing larvae in terms of microclimate, host plant chemistry and phenology, or avoiding of parasitoids (e.g., Weiss et al., 1988; Warren, 1987; Osborne \& Redak, 2000). Narrow larval requirements combined with limited adult dispersal are associated with the vulnerability of many Melitaeini species in Europe (e.g., Warren, 1994; Wahlberg et al., 1996).

The Marsh Fritillary (Euphydryas aurinia Rottemburg, 1775 ) is threatened in most of Europe and is listed in the Berne Convention and in the EEC/EU Habitat Directive.
It inhabits seminatural meadows, habitats that are declining continentally due to the intensification of grazing, land drainage, improvements of grasslands and afforestation schemes (Van Sway \& Warren, 1999). The biology of the butterfly has been studied in several regions (e.g., Warren, 1994; Lewis \& Hurford, 1997; Munguira et al., 1997; Wahlberg et al., 2002a, b). The studies pointed to marked geographical variation in habitat use and range of host plants (cf. Descimon et al., 2001; Singer et al., 2002). The message for conservation is that approaches useful in one part of a species' range may be impractical, or even harmful, in other geographical areas.

Until recently, little was known about $E$. aurinia in the Czech Republic. Mašek (1987) showed that the sole host plant of Czech populations is the Devil's Bit Scabious, Succisa pratensis (Moench, 1794). This contrasts with many other parts of Europe, including nearby Bavaria, where some populations utilise alternative hosts. However, the restricted distribution and recent decline of Czech populations cannot be attributed to a rarity of the locally-used host plant, which has a much wider distribution than the butterfly in this country.

\footnotetext{
* Corresponding author. E-mail: konva@tix.bf.jcu.cz
} 


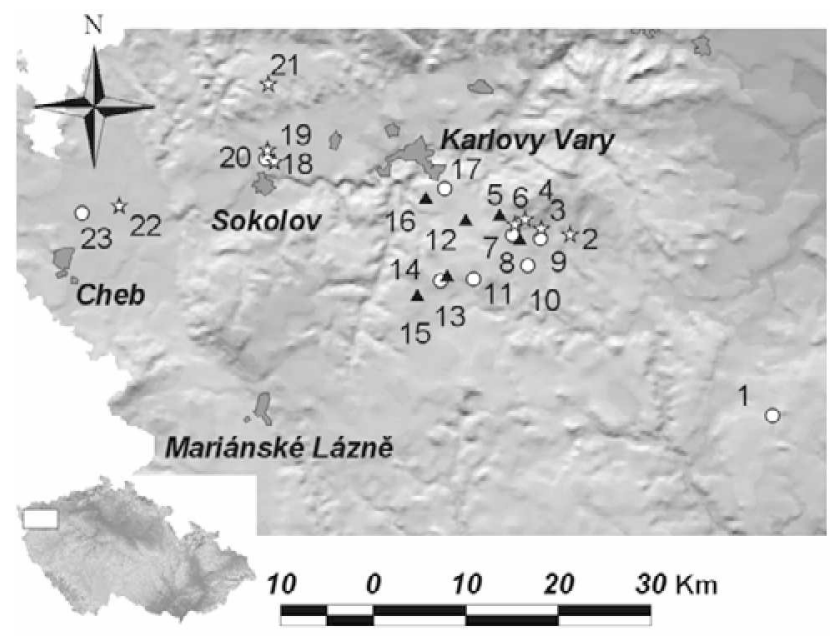

Fig. 1. Map showing the location of the study area in the Czech Republic (left lower corner) and distribution of study sites. The Tepelská Highlands is the dense cluster of sites southeast from Karlovy Vary. The symbols denote occupied and intensively sampled sites (white circles), occupied and nonintensively sampled sites (black triangles), unoccupied (i.e., Succisa present but the butterfly absent), and nonintensively sampled sites (white stars).

In this paper, we focus on the differences between host plants occupied and unoccupied by pre-diapause larvae. As in other Melitaeini species, larvae of $E$. aurinia live gregariously until hibernation, forming conspicuous silken nests on their host plant. The gregarious habit facilitates the study of the distribution of the nests, which reflects both the flight and oviposition preferences of adult females. It is known that an understanding of the precise conditions preferred by ovipositing females (and their developing larvae) may be crucial for the efficient conservation of specialised butterflies (e.g., Gutierrez et al., 1999; Kopper et al., 2000). Hence, nest counts are regularly used to assess habitat suitability and site occupancy by Melitaeinae butterflies (Hanski, 1999; Wahlberg, 2000, 2002).

Our principal questions were, first, how is the occurrence of larvae related to the composition of vegetation, and second, how is it related to the structural traits (= architecture) of the host plants. We focused on these within-site patterns of "habitat quality" (e.g., Weiss et al., 1988; Thomas et al., 2001), disregarding such spatial aspects of site occupancy as habitat connectivity, which will be analysed elsewhere. We compared the composition of the vegetation around occupied and unoccupied host plants, constructed regression models relating presence of larval nests to host plant architecture, and used the results to infer guidelines for management of $E$. aurinia sites.

We expected that the following patterns might influence the suitability of host plants for E. aurinia larvae. First, since the larvae feed gregariously and food scarcity causes mortality in a related species (White, 1974), the nests should be found either on large Succisa plants, or on those growing in dense swards. Second, the larvae feed in late autumn and early spring, so their survival depends on frequent basking (Porter, 1982, 1984), which may be hindered in shaded conditions where tall vegetation surround the host plants. Third, the butterfly inhabits humancreated meadows and hence depends for its survival on the ongoing management of its habitats (Bulman, 2002). Since one of the effects of abandonment is that some plant species are deprived of germination opportunities, we also hypothesised that the lack of management may be counterbalanced by small-scale soil disturbance (cf. Krenova \& Leps, 1996).

\section{MATERIAL AND METHODS}

\section{Study system}

E. aurinia is a univoltine species, the adults fly from late May until late June in the Czech Republic. Females lay egg batches on young leaves of Succisa pratensis, and the larvae live gregariously in nests spun on the host plants prior to hibernation, and become solitary in spring.

The butterfly has never been common in the Czech Republic. Its range has declined by $67 \%$ during the past century, as measured by the number of atlas grid cells it occupies (Hula et al., in press). It is now restricted to western Bohemia (= the western part of the Czech Republic), where it occurs in 11 grid cells, forming 14 distinct colonies/clusters of colonies in humid grasslands. Half of them are abandoned meadows threatened by succession, the rest are either extensive pastures or infrequently mown meadows. A recent (2002) survey of the 14 colonies showed that only three of them contained more than one hundred larval nests, while four contained less than ten nests.

The host plant Succisa pratensis has a scattered distribution throughout most of the Czech Republic. Habitats of the plant include xeric to damp unimproved meadows, pastures and light forests. Štěpánek \& Holub (1997) mentioned a decline of the plant due to land drainage in the 1970 s and 1980 s, but the distribution of the plant is still much wider than that of the butterfly.

\section{Data collecting}

Study sites. Most of fieldwork was done in the Tepelská Highlands in Western Bohemia, the Czech stronghold of E. aurinia (Fig. 1). It is a sparsely populated hilly (alt. 500-700 m) mosaic of pastures for meat cattle, low-intensity crop fields and spruce plantations. Four colonies of $E$. aurinia were known in the area prior to this study. We sampled all of them and searched for other remnants of traditionally used or abandoned seminatural meadows and pastures, using topographic maps and aerial photographs. We discovered and sampled 15 occupied and 8 unoccupied sites with Succisa pratensis. We also sampled three extant and isolated sites outside of the area: on the outskirts of the lignite mines in Sokolov (Fig. 1: sites 18-20), in the Soos reserve (23), and near Rakovník (1), plus two historical and recently vacant sites, one in the Krušné Mts. (21) and one near Česká Lípa (50³0', outside the range of the map).

Sampling design. We did not sample all the 23 sites with equal intensity. Nine sites (herein "intensive"; Fig. 1) were sampled along linear transects that transversed the densest growths of the host plant. In September 4-8, 2000 (sites 3 and 20) and in August 28-September 6, 2001 (the remaining sites), we measured ca 100 (mean 130, median $=99, \mathrm{SD}=52.6$, range 55-349) successive host plants in a 1-metre strip along the transects. For each plant, we recorded the presence of a larval nest and the host plant architecture variables listed in Table 1 . We also recorded the vegetation around every fourth or fifth plant, obtaining 20-25 samples per site. 
TABLE 1. Explanatory variables used in the ordination and regression analyses used to compare Succisa pratensis plants occupied and unoccupied by larvae of Euphydryas aurinia.

\begin{tabular}{|c|c|c|c|c|}
\hline Variable & Describing & Type & Description & used in* \\
\hline ALTITUDE & sites & continuous & & $\mathrm{C}$ \\
\hline HOSTPLANT & sites & ordinal & abundance of Succisa on a site (assessed on log scale) & $\mathrm{C}$ \\
\hline MANAGEMENT & sites, plots & $\begin{array}{l}\text { categorical (4) } \\
\text { fuzzy coding }\end{array}$ & $\begin{array}{l}\text { GRAZING, MOWING, ABANDONED, RUDERAL } \\
\text { (fuzzy if a site had more regimes) }\end{array}$ & $\mathrm{C}$ \\
\hline COVER_HO & plots & continuous & cover of moss layer in vegetation samples & $\mathrm{C}$ \\
\hline COVER_H1 & plots & continuous & cover of herb layer in vegetation samples & $\mathrm{C}$ \\
\hline COVER_H2 & plots & continuous & cover of shrubs and trees in vegetation samples & $\mathrm{C}$ \\
\hline BARREGR & plots & continuous & amount of bare ground in vegetation samples & $\mathrm{C}$ \\
\hline SUN/SHADOW & sites, plots & binomial & sunny vs. shady position of a plot/plant & $\mathrm{C}$ \\
\hline SURRHE & plots, plants & ordinal $(1-5)$ & $\begin{array}{l}\text { height of vegetation in plots or around Succisa plants } \\
1:<10 \mathrm{~cm}, 2:<25 \mathrm{~cm}, 3:<0.5 \mathrm{~m}, 4:<1 \mathrm{~m} \text {, and } 5:>1 \mathrm{~m}\end{array}$ & $\mathrm{C}$ \\
\hline HEIGHT & plants & continuous & height of the tallest shoot of Succisa plant & A \\
\hline SHOOTS & plants & continuous & number of shoots produced by Succisa plant & A \\
\hline FLOWERS & plants & continuous & number of inflorescences produced by Succisa plant & A \\
\hline DAMAGE & plants & binomial & plant damaged by animals, vehicles, trampling etc. & A \\
\hline CLOSE_DIST & plants & continuous & distance to the closest Succisa plant & A \\
\hline AVER_DIST & plants & continuous & mean distance to three closest Succisa plants & A \\
\hline
\end{tabular}

*C: variable used in ordinations of vegetation composition; A: variable used in regressions of vegetation architecture

At the remaining 14 "nonintensive" sites (eight of them unoccupied), we recorded the data for only ca 20 host plants (mean = 20 , median $=16, S D=5.9$, range $15-38$ ). While selecting the plants, we always followed the same routine. We first thoroughly searched for the presence of nests at each site. If the site was occupied, we then located and sampled 5-7 occupied plants, and finally randomly sampled unoccupied plants up to the final number. In a few very small sites, all the plants were sampled. The rationale was to keep the proportion of occupied and unoccupied plants close to that recorded from the intensive sites and to as completely as possible the variation in the unoccupied plants.

In the text, we refer to intensive and nonintensive data, and to "total" data, which consists of the two data sets combined.

For the analyses of vegetation composition, we sampled 497 circular plots of one metre diameter around selected host plants (116 occupied by nests, 381 unoccupied). We recorded percentage covers of all the vascular plants within the plots, plus percentage of moss and of bare ground. Thus sampled plots were either those along the intensively sampled transects $(\mathrm{N}=$ $169)$, or the non-intensive sites $(\mathrm{N}=328)$. For analyses of effects of host plant architecture, we collected data from 1450 Succisa plants (intensive, $\mathrm{N}=1165$; nonintensive, $\mathrm{N}=285$ ), 170 of them occupied (intensive: 118; nonintensive: 52).

Explanatory variables. Table 1 lists the explanatory variables recorded during the sampling. Different variables were used in the analyses of vegetation composition and vegetation architecture, but there was some overlap if a variable was appropriate for both analyses.

Some of the variables, such as ALTITUDE or types of the management, characterise sites rather than sampling plots or individual plants. Use of such variables in analyses that focus on within-site patterns in fact constitutes pseudoreplications. To mitigate against this problem, we entered a covariable describing the identity of individual sites into all statistical models that included site-describing explanatory variables. Wherever appropriate, we also controlled for the potentially confounding effects of sampling INTENSITY and the PERSON who collected the data (V.H. versus M.K.).

\section{Statistical analyses}

Ordination of vegetation composition. We used the redundancy analysis (RDA) in CANOCO for Windows (Ter Braak \& Smilauer, 2002) to relate the composition of Succisasurrounding vegetation to occupancy by larval nests. The RDA is a linear constrained ordination method that relates the "species" composition of samples to external "environmental" variables. CANOCO allows for inclusion of co-variables and for fuzzy coding of environmental variables. It tests the significance of the ordination results by means of the Monte Carlo Permutation test. We ran the tests with log-transformed plant covers in individual samples, scaling focused on inter-species correlations, species scores divided by the standard deviation and species centered by species scores. $S$. pratensis, which was present in all samples, was ignored in the analysis ("supplementary species" in CANOCO) and we standardised the compositions of samples by sample norms to obtain a more equal sample total.

We first asked whether the occupied and unoccupied plots differed in species composition. The presence/absence of nests was the independent variable in the analyses, which we run both with- and without controlling for the effects of SITE and INTENSITY.

Second, we asked whether the environmental variables influencing the composition of the vegetation in individual plots predict the presence of nests. We did this by mapping nest presence onto ordination models constructed for vegetation via the generalised linear modelling (GLM) procedure in CanoDraw for Windows 4.5 (Ter Braak \& Smilauer, 2002). We first constructed ordination models of plant species composition, selecting the most parsimonious sets from the "ordination" variables (Table 1 ) via the forward selection procedure $(\alpha-$ level $=0.05)$. Subsequently, we constructed GLMs that mapped the presence of nests within plots (binary-coded dependent variable) onto the 


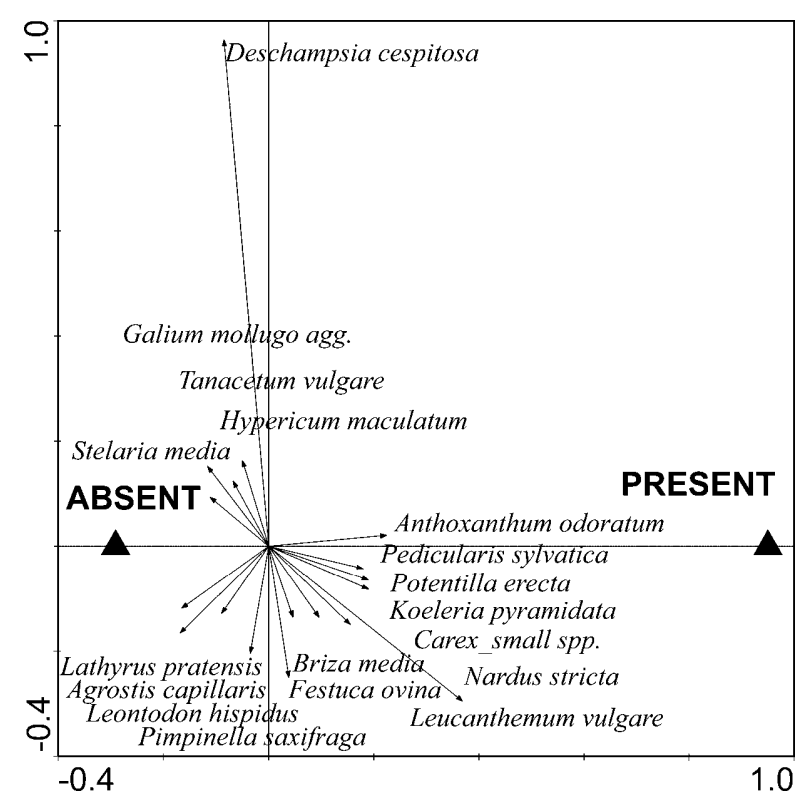

Fig. 2. Ordination diagram of the redundancy analysis of plant species composition of plots occupied (PRESENT) and unoccupied (ABSENT) by larval nests of Euphydryas aurinia. Total data, nest presence entered as binary variable. The first (horizontal) axis separates, highly significantly, occupied and unoccupied plots (eigenvalue $=0.023, \mathrm{~F}=11.9, \mathrm{p}<0.001$ ) Only plants with minimum fit $=2$ are depicted, the strength of the correlation between plant species and nest presence/absence is approximated by the angle between the arrows for individual plants and the first ordination axis. The same patterns were found in the nonintensive (eigenvalue $=0.013, \mathrm{~F}=4.4, \mathrm{p}<$ 0.001 ) and intensive (eigenvalue $=0.042, \mathrm{~F}=7.2, \mathrm{p}<0.001$ ) data.

ordination models using quadratic-level functions, which achieved superior fits for all modelled situations according to the Akaike information criterion (AIC).

Indicator values. We used Ellenberg's indication values for individual plant species to further evaluate the composition of the vegetation surrounding nests. The values describe, on ordinal scales, the ecological requirements of higher plants of the Central European flora (Ellenberg, 1979) and correlate well with measured values (e.g., Schaffers \& Sykora, 2000; Wamelink et al., 2002).

We used the indicator values for light, temperature, humidity, $\mathrm{pH}$ and nitrogen given in Frank \& Klotz (1990) for testing the null hypothesis that samples containing and not containing nests do not differ in these conditions. The dependent variables were mean indicator values per plot weighted by the cover of individual species (including $S$. pratensis, because its relative abundance in the plots could also reflect habitat properties). Since Frank \& Klotz (1990) did not provide indicator numbers for "indifferent" plants, we substituted the missing values with means obtained from all species represented in individual samples, for which the values are given by the authors. We did the same for several small sedges (Carex spp.), not identified to species.

Regressions of host plant architecture. To assess the effects of structural traits and position of host plants on presence of larval nests, we constructed multiple regression models with nest presence as the dependent variable with a binomial distribution. We used the GLM procedure in S-plus 2000 (1999). We first assessed the separate effects of the covariables SITE, YEAR and PERSON, and of all potential explanatory variables (Table 1). For continuous and ordinal variables, we checked the linearity of the relationships by constructing the regressions also as second-degree polynomials and logs, and selecting the most appropriate model using the AIC values.

Following the single-term tests, we constructed multiple regression "BEST" models for intensive, nonintensive and total data. The procedure involved constructing models with all the possible explanatory variables (without interactions), from which we successively excluded redundant variables using the S-plus' "dropl" function while retaining the (nominally significant) effects of SITE in the models. After obtaining a model with no redundant terms, we iteratively added and deleted all possible multiple-term interactions, until we found a model for which neither adding nor dropping of terms improved its (AICevaluated) fit.

\section{RESULTS}

\section{Composition of vegetation}

The plots containing larval nests had a higher cover of Succisa pratensis $($ Mean $=36, \mathrm{SD}=18.1$, median $=30$, range $=5-90)$ than unoccupied plots $($ Mean $=30, \mathrm{SD}=$ 20.1 , median $=30$, range $=2-90)($ Mann-Whitney $\mathrm{U}: \mathrm{p}<$ $0.001)$. Thus, the occurrence of $E$. aurinia nests was associated with a high cover of the host plant.

Still, the RDA ordination revealed highly significant difference in plant species composition between occupied and unoccupied plots (Fig. 2). The explained variance was small, but the larval nests were clearly positively associated with certain plants. Occupied plots contained a higher cover of short graminoids, such as Nardus stricta, Anthoxantum odoratum and "small" Carex sedges, and of subordinate herbs (e.g., Veronica officinalis, Plantago lanceolata, Pedicularis sylvatica). Unoccupied plots had a higher cover of tall grasses, most notably Deschampsia cespitosa, and of vigorous tall herbs (e.g., Cirsium heterophylum, Hypericum maculatum). Controlling for SITE and INTENSITY (results not shown) did not change the pattern.

The composition of the vegetation within plots was influenced by both SITE (sum of all eigenvalues $=0.167$, $\mathrm{F}=6.0, \mathrm{p}<0.001$ ) and sampling INTENSITY (eigenvalue $=0.020, F=9.9, p<0.001$ ), suggesting considerable variation among sites. However, after considering the two effects as co-variables, the external variables that significantly explained composition of the vegetation were related significantly to the presence of nests (Table 2 ). The vegetation-describing variables typically picked up by forward selection procedures were related to site management either directly (e.g., GRAZING, ABANDONED) or indirectly (e.g., SURRHE, SUN; management clearly affects sward height or level of shading). As suggested by the GLM-mapping of nest presence on the ordination axes, likelihood of nest presence decreased with height of sward (Fig. 3), which was low at managed sites and tall at abandoned sites.

\section{Indicator values}

The comparison of mean Ellenberg's indicator values for occupied $(\mathrm{N}=116)$ versus unoccupied $(\mathrm{N}=381)$ 


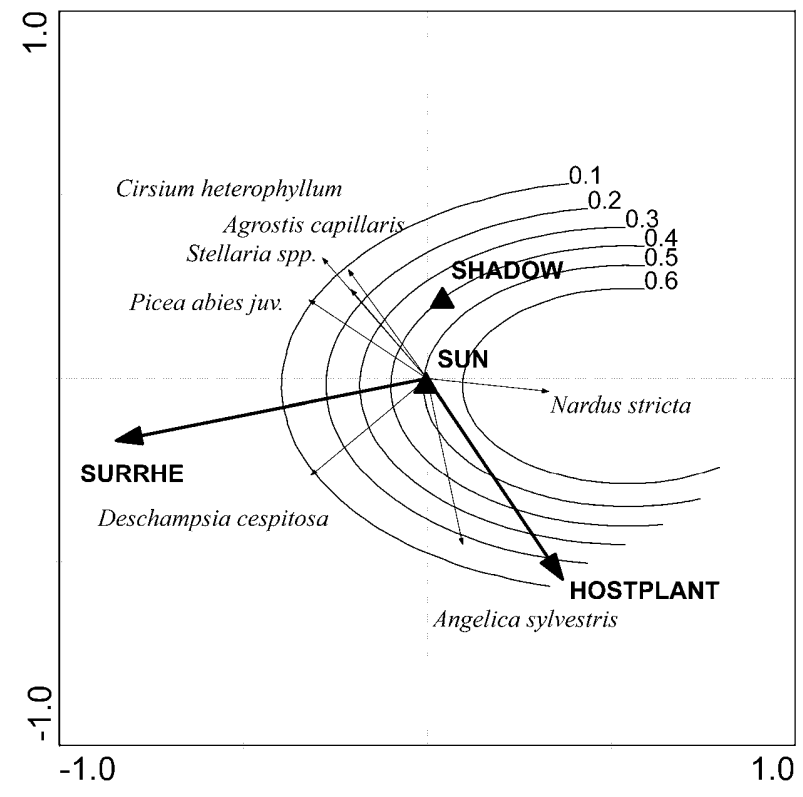

Fig. 3. GLM-mapping of the occurrence of larval nests of Euphydryas aurinia on results of RDA ordination of vegetation composition. Intensive data, not controlled for covariables. Quadratic-degree binomial model of nest occurrence. Ordination of vegetation was constrained by explanatory variables describing the plots and study sites, variation attributable to differences between sites was controlled by including individual sites as covariables, explanatory variables were selected by forward selection procedure. The isolines show probability of occurrence of the nests, as fitted by the models. Refer to Table 1 for definition of variables.

plots showed that the nests occurred in plots that were drier and had a lower $\mathrm{pH}$ and nitrogen content. (Humidity: $\mathrm{t}=-3.10, \mathrm{p}<0.01 ; \mathrm{pH}: \mathrm{t}=-6.74, \mathrm{p}<0.0001$; Nitrogen, $\mathrm{t}=-6.17, \mathrm{p}<0.0001)$. No differences were found in mean values for light $(\mathrm{t}=1.41,495$ d.f., $\mathrm{p}=$ $0.16)$ and temperature $(t=-1.28, p=0.20)$.

\section{Host plant architecture}

The single-term regressions of nest presence against host plant architecture (Table 3) revealed that nests occurred more frequently on plants growing in dense swards (i.e., the variables AVER DIST and CLOSE_DIST). The positive association between nest presence and numbers of shoots and/or inflorescensces (the two were correlated, $r=0.64$ and $p<0.001$ ) suggested that occupied plants tended to be richly branched. In contrast, plant height showed either no (total and intensive data) or a negative (nonintensive data) association with occupancy. Occurrence of the nests was consistently influenced by the 2nd-order polynomial of height of surrounding vegetation: the likelihood of nest occurrence peaked between 25 and $50 \mathrm{~cm}$ and decreased in taller swards (Fig. 4). The positive effect of DAMAGE manifested itself in the "intensive" and "nonintensive" data. Neither YEAR nor RECORDER influenced the results.

Each of the multiple-regression "BEST" models (Table 4, Fig. 4) showed that even after controlling for differences between sites, the presence of nests was positively associated with density of host plants. Other variables predicting the occurrence of nests were number of shoots/inflorescences, the 2nd-order polynomial of sward height, and damaged plants. The higher-order interaction that improved the fit of the models suggested that shade counterbalanced the positive associations with host plant density. The absence of a relationship with sward height in the intensive data was presumably caused by the fact that at all the intensively sampled sites, there were strong larval populations of the butterfly, and thus probably the optimal sward height.

\section{DISCUSSION}

The presence of prediapause larval nests of Euphydryas aurinia on Succisa pratensis was positively associated with a high cover of the host plant, and of short grasses and competitively subordinate herbs surrounding the host plants. It was negatively associated with competitively superior tall grasses and herbs. The nests were common at sites with relatively short sward, which is typically maintained by mowing or light grazing, and on host plants growing in drier and nitrogen-poor conditions. Analysis of host plant architecture confirmed the association of nests with densely clumped host plants growing in low to medium-height vegetation. The different analytical approaches gave similar results. For instance, a higher host plant cover corresponded with a high number of shoots/flowerheads of occupied plants.

TABLE 2. Summary of the redundancy analyses of the composition of vegetation surrounding Succisa pratensis plants, and GLMmapping of the presence of nests of Euphydryas aurinia within plots on the ordination models. All the GLM models were constructed as quadratic-level functions.

\begin{tabular}{|c|c|c|c|c|c|c|c|c|}
\hline \multirow{2}{*}{$\begin{array}{l}\text { Vegetation composition model } \\
\text { (vegetation } \sim \text { [explanatory variables] / [covariables] }\end{array}$} & \multicolumn{2}{|c|}{ 1st ordination axis } & \multicolumn{2}{|c|}{ all axis } & \multicolumn{4}{|c|}{ GLM for nest presence } \\
\hline & eigenvalue & $\mathrm{F}$ & Trace & $\mathrm{F}$ & $\%$ dev & d.f. & AIC & $\mathrm{F}$ \\
\hline \multicolumn{9}{|l|}{ Total data } \\
\hline$\sim($ GRAZING+MOWING+ABANDONED+ SURRHE)/(SITE) & 0.022 & $12.8^{* * *}$ & 0.041 & $8.3 * * *$ & 13.6 & 4,490 & 475 & $20.1^{* * *}$ \\
\hline$\sim($ GRAZING+MOWING+ABANDONED+SURRHE)/(SITE+INTENS. $)$ & 0.021 & $12.6^{* * *}$ & 0.041 & $8.3 * * *$ & 13 & 4,490 & 477.9 & $19.4^{* * *}$ \\
\hline \multicolumn{9}{|l|}{ Nonintensive data } \\
\hline$\sim(\mathrm{ABANDONED}+\mathrm{GRAZING}+\mathrm{MOWING}+\mathrm{SUN}+\mathrm{SURRHE}) /(\mathrm{SITE})$ & 0.023 & $9.1 * * *$ & 0.054 & $5.5 * * *$ & 14 & 4,323 & 258.9 & $10.9^{* * *}$ \\
\hline \multicolumn{9}{|l|}{ Intensive data } \\
\hline$\sim($ SUN+HOSTPLANT+SURRHE $) /($ SITE $)$ & 0.042 & $8.3 * * *$ & 0.08 & $5.6^{* * *}$ & 20.1 & 4,162 & 186.6 & $11.4^{* * *}$ \\
\hline
\end{tabular}

\%dev: the percentage of null model deviance attributable to the fitted model. ${ }^{* * * *} \mathrm{p}<0.001$ 
TABLE 3. Results of single-term binomial GLM regressions of nest occupancy against architecture and position of Succisa pratensis host plants. The darts indicate the direction of the relationships. The significance values refer to testing for a significant decrease of deviance of fitted models, tested using F-tests against the null models: Nest presence $=\beta_{0}+$ error. See Table 1 for description of variables.

\begin{tabular}{|c|c|c|c|c|c|c|c|c|c|c|c|c|}
\hline \multirow{2}{*}{$\begin{array}{l}\text { Model } \\
\text { (nest presence } \sim \text { ) }\end{array}$} & \multicolumn{4}{|c|}{ Total data } & \multicolumn{4}{|c|}{ Intensive data } & \multicolumn{4}{|c|}{ Nonintensive data } \\
\hline & & d.f. & deviance & $\mathrm{p}$ & & d.f. & deviance & $\mathrm{p}$ & & d.f. & deviance & $\mathrm{p}$ \\
\hline (null model) & & 1449 & 1048.0 & - & & 1164 & 764.0 & - & & 284 & 270.8 & \\
\hline$\sim$ SITE & & 22,1427 & 930.1 & $* * * *$ & & 8,1156 & 731.9 & $* * * *$ & & 14,270 & 202.2 & $* * * *$ \\
\hline$\sim$ YEAR & & 1,1448 & 1045.2 & + & & 1,1163 & 763.9 & n.s. & & - & - & - \\
\hline RECORDER & & 1,1448 & 1047.5 & n.s. & & 1,1163 & 760.0 & n.s. & - & 1,283 & 270.8 & n.s. \\
\hline$\sim$ SUN & $\uparrow$ & 1,1448 & 1044.4 & + & $\uparrow$ & 1,1163 & 760.4 & + & - & 1,283 & 269.8 & n.s. \\
\hline$\sim$ SURRHE & $\downarrow \uparrow \downarrow$ & $2,1447^{\mathbf{P}}$ & 1023.9 & ${ }^{* * * *}$ & $\downarrow \uparrow \downarrow$ & $2,1162^{\mathrm{P}}$ & 755.4 & $*$ & $\downarrow \uparrow \downarrow$ & $2,282^{\mathrm{P}}$ & 241.1 & ***** \\
\hline AVER_DIST & $\downarrow$ & $1,1448^{\mathrm{L}}$ & 990.5 & $* * * *$ & $\downarrow$ & $1,1163^{\mathbf{L}}$ & 750.5 & $* * * *$ & $\downarrow$ & 1,283 & 180.3 & $* * * *$ \\
\hline$\sim$ CLOSE_DIST & $\downarrow$ & 1,1448 & 1005.7 & $* * * *$ & $\downarrow$ & 1,1163 & 752.5 & ${ }^{* * * *}$ & $\downarrow$ & 1,283 & 205.8 & ${ }^{* * * *}$ \\
\hline$\sim$ DAMAGE & $\uparrow$ & 1,1448 & 1041.8 & $*$ & - & 1,1163 & 762.6 & n.s. & $\uparrow$ & 1,283 & 250.2 & $* * * *$ \\
\hline HEIGHT & - & 1,1448 & 1047.8 & n.s. & - & 1,1163 & 762.8 & n.s. & $\downarrow$ & 1,283 & $252.2^{\mathrm{L}}$ & $* * *$ \\
\hline$\sim$ SHOOTS & $\uparrow$ & 1,1448 & 1042.7 & * & $\uparrow$ & 1,1163 & 760.2 & * & - & 1,283 & 270.7 & n.s. \\
\hline$\sim$ FLOWERS & $\uparrow$ & 1,1448 & 1043.0 & * & $\uparrow$ & 1,1163 & 760.2 & $*$ & - & 1,283 & 270.8 & n.s. \\
\hline
\end{tabular}

ANOVA test of significance of model terms: ${ }^{+} \mathrm{p}<0.1,{ }^{*} \mathrm{p}<0.05,{ }^{* * *} \mathrm{p}<0.01,{ }^{* * *} \mathrm{p}<0.001,{ }^{* * * * *} \mathrm{p}<0.0001$.

Pdependent variable entered as 2 nd-degree polynomial; ${ }^{\mathbf{L}}$ dependent variable entered as natural $(\mathrm{ln})$ logarithm.

The ordination and regression models explained relatively very little of the variation. However, the results were significant after controlling for covariables, and thus quite robust. In contrast to this study, many authors who compared occupied and unoccupied butterfly host plants worked with equal numbers of samples in the two categories (e.g., Bourn \& Thomas, 1993; Kopper et al., 2000). We kept the proportions of the two categories nearly

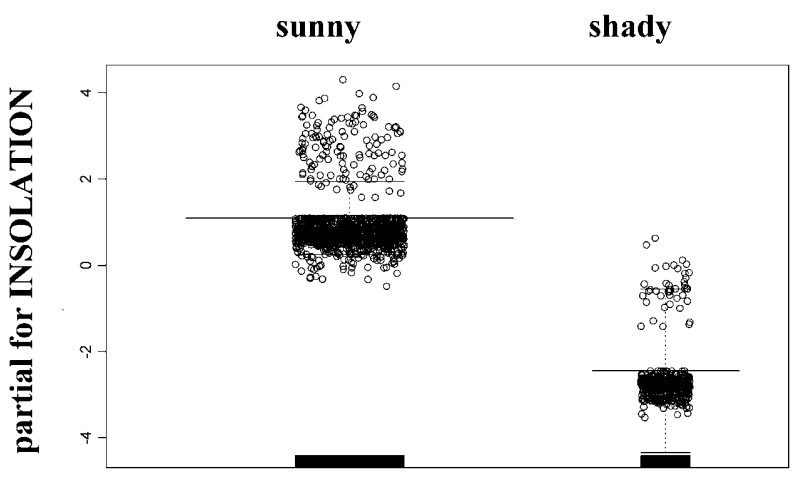

INSOLATION

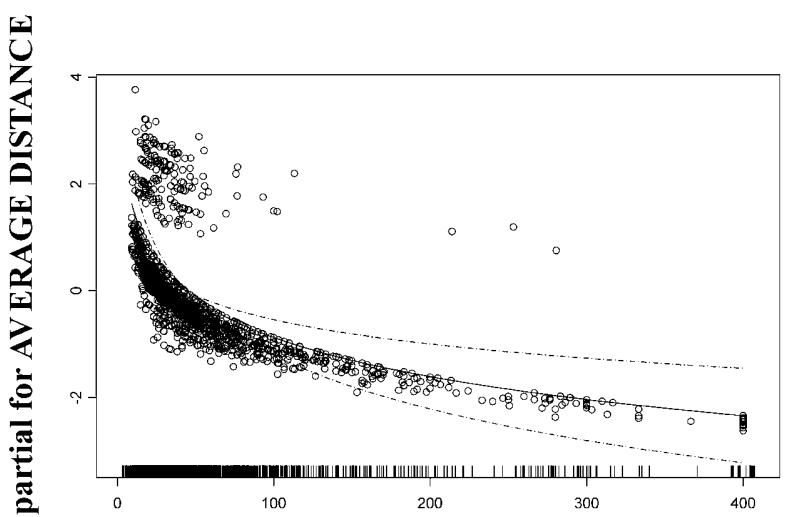

AVERAGE DISTANCE (cm)

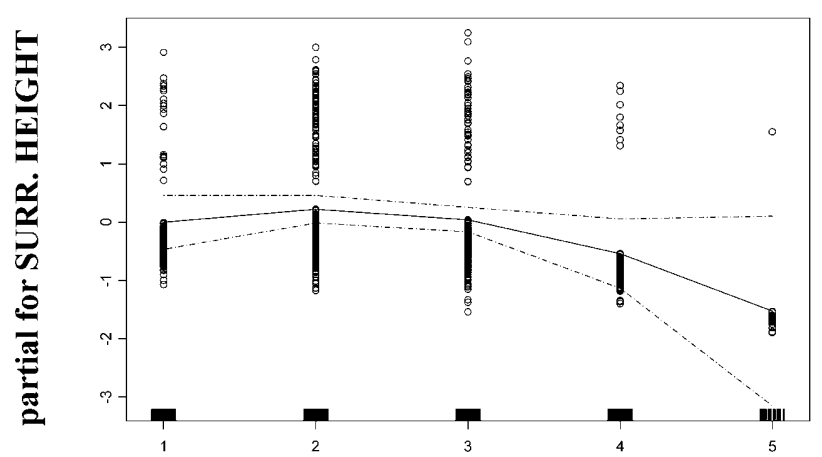

HEIGHT OF SURR. VEGETATION

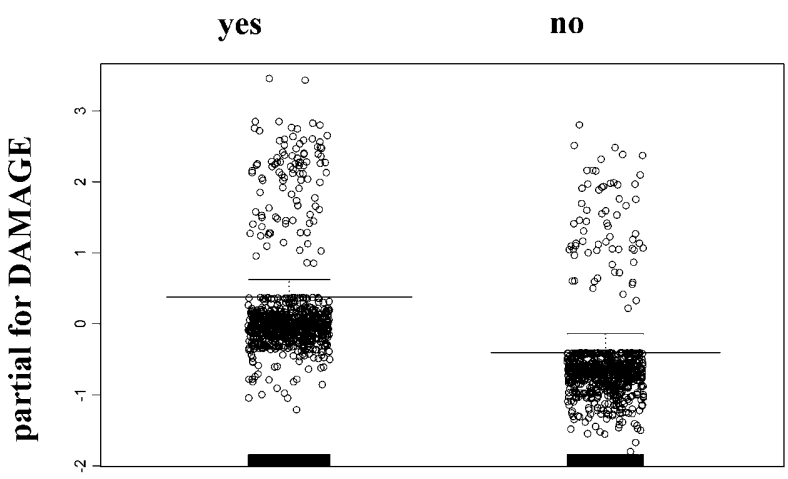

DAMAGE

Fig. 4. Multiple GLM-regression of the occupancy (binary dependent variable) of Succisa pratensis plants by larval nests of Euphydryas aurinia. Total data, variation attributable to differences between sites controlled by considering the identity of the sites as a covariable. The plots show partial effects of individual model terms (without interactions) on nest occurrence. 
TABLE 4. Multiple GLM regressions of the nest occupancy of Succisa pratensis plants against the architecture of the plants. Models BEST1 contain significant covariable SITE, and the remaining terms are those that remained significant after considering variability due to differences between sites. The darts indicate direction of the relationships of individual terms.

\begin{tabular}{|c|c|c|c|c|c|c|c|c|c|c|c|c|c|c|c|c|c|}
\hline \multicolumn{6}{|c|}{ Total data } & \multicolumn{6}{|c|}{ Intensive data } & \multicolumn{6}{|c|}{ Nonintensive data } \\
\hline model terms & & d.f. & dev. & $\%$ & $\mathrm{p}$ & model terms & & d.f. & dev. & $\%$ & $\mathrm{p}$ & model term & & d.f. & dev. & $\%$ & $\mathrm{p}$ \\
\hline Null & & 1449 & 1048 & 100.0 & & Null & & 1164 & 764.0 & 100.0 & & Null & & 284 & 270.8 & 100.0 & \\
\hline SITE & & 22 & 930.1 & 11.3 & * & SITE & & 8 & 731.9 & 4.2 & $*+*$ & SITE & & 13 & 198.2 & 26.8 & 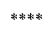 \\
\hline SUN [1] & $\uparrow$ & 1 & 922.6 & 0.7 & $* * *$ & SUN [1] & $\uparrow$ & 8 & 723.8 & 1.1 & $* *$ & SURRHE $^{\mathrm{P}}$ & $\downarrow \uparrow \downarrow$ & 2 & 168.4 & 11.0 & $* * * *$ \\
\hline SURRHE ${ }^{P}$ & $\downarrow \uparrow \downarrow$ & 2 & 897.1 & 2.4 & intete & AVER_DIST ${ }^{\mathrm{L}}$ [2] & $\downarrow$ & 1 & 698.2 & 3.3 & woted & AVER_DIST & $\Gamma \downarrow$ & 1 & 110.5 & 21.4 & wteiter \\
\hline AVER_DIST ${ }^{\mathrm{L}}[2]$ & $\downarrow$ & 1 & 839.9 & 5.5 & ** & SHOOTS & $\uparrow$ & 1 & 681.9 & 2.1 & $* * *$ & DAMAGE & $\uparrow$ & 1 & 99.9 & 3.9 & ***** \\
\hline DAMAGE & $\uparrow$ & 1 & 827.1 & 1.2 & ** & {$[1]^{*}[2]$} & & 1 & 678.7 & 0.4 & + & SHOOTS & $\uparrow$ & 1 & 97.3 & 1.0 & ****t \\
\hline$[1]^{*}[2]$ & & 1 & 805.9 & 2.0 & * & BEST & & 12 & 678.7 & 11.2 & $* * * * *$ & BEST & & 18 & 97.3 & 64.1 & $* * * * *$ \\
\hline BEST & & 29 & 805.9 & 23.1 & $* * * * *$ & & & & & & & & & & & & \\
\hline
\end{tabular}

ANOVA test of significance of model terms: ${ }^{+} \mathrm{p}<0.1,{ }^{*} \mathrm{p}<0.05,{ }^{* *} \mathrm{p}<0.01,{ }^{* * *} \mathrm{p}<0.001,{ }^{* * * *} \mathrm{p}<0.0001$.

${ }^{P}$ dependent variable entered as 2 nd-degree polynomial; ${ }^{\mathbf{L}}$ dependent variable entered as natural $(\ln ) \log \operatorname{lorithm}$.

identical (nonintensive data) or identical (intensive data) to the situation in field. The price was the low explained variability, but the advantage was higher biological realism.

\section{Host plant and larval requirements}

The occurrence of nests agreed well with the preferences of the host plant, Succisa pratensis. The plant is an inferior competitor (Buhler \& Schmid, 2001; Pauli et al., 2002) prospering in nutrient-poor grasslands. In speciesrich meadows of Central Europe, competition is for light rather than nutrients. Superior species turn nutrients into biomass more efficiently, overgrowing inferior species and depriving them of light (Leps, 1999) and germination opportunities (cf. Kotorova \& Leps, 1999).

The finding of a close match between occurrence of larval nests and optimal conditions for the host plant is not a trivial one. Many European butterflies prefer just the opposite, i.e., host plants growing in suboptimal conditions (e.g., Sparks et al., 1994; Bergman, 1996). Prominent discrepancies between the ecological optima of host plants and butterfly larvae are known for several checkerspot butterflies (e.g., Thomas \& Simcox, 1982; Warren, 1987; Hanski \& Singer, 2001), including species of the genus Euphydryas (e.g., Singer, 1983; Singer \& Parmesan, 1993). Since no such discrepancy applies to the association between $S$. pratensis and $E$. aurinia, it might indicate that an abundance of the plant should ensure the well being of the butterfly.

However, abundance is not enough. The plants grew in a broader range of humidity, $\mathrm{pH}$, nitrogen, and sward height conditions in the studied area than was occupied by the nests. Presence of nests did not correlate with total host plant abundance per site in the ordinations, but rather with such factors as the height of vegetation and the management (Fig. 3). The nests were also scarce on the tallest host plants (see Table 3, nonintensive data). S. pratensis grows tall and develops fewer shoots when shaded. This happens at abandoned sites invaded by shrubs and young trees, or in distant corners of meadows and pastures that are mown or grazed less frequently. Hence, abandonment leads to conditions that are - for a time - still tolerable for the host plant, but intolerable for the larvae. Wahlberg et al. (2002b) observed that $S$. pratensis growing in forest clearings becomes unsuitable for $E$. aurinia after a few years of forest regrowth.

The above observations agree with the effect of the variable "DAMAGE" in regression models. Damaged plants of Succisa were typically found at sites mechanically disturbed by animals (boar wallows, cattle paths), in tractor tracts, or along lightly trampled paths. Disturbed soil at such sites presumably facilitates the germination of the plant, allowing it to form dense swards.

We found several nests at unexpected sites: xeric banks of a drainage channel (site 12 in Fig. 1, 1 nest), improved pasture sown with fodder mixture (site 12, 3 nests) and edge of a slag heap (site 5, 2 nests). Although any inference from such observations is speculative, occurrence of nests at such sites again suggested that sunny and low sward conditions were crucial for larval development. In some parts of Europe, populations of $E$. aurinia inhabit drier grasslands, where they use host plants other than $S$. pratensis (cf. Singer et al., 2002). It may be just chance that the populations in Western Bohemia lack the ability to utilise a broader range of potential hosts, and thus can not extend their range to more xeric conditions.

\section{Larval or female preferences?}

The patterns in the distribution of larval nests agreed with our initial hypotheses. Low nitrogen and humidity (and correlated low $\mathrm{pH}$ ) result in a short sward with cussion-forming grasses (such as Nardus stricta). Such conditions should facilitate larval basking and the high host density makes it unlikely that the larvae will starve. The occupied sites thus were in many respects ideal for larval development. However, it is not the larvae, but the egg-laying females that determine the occurrence of nests. How can they recognise in June that a site will be suitable for larvae from September until spring of the next year? 
By definition, each female emerges at a good site. If local conditions remain stable from year to year, females should restrict egg laying to natal sites to choose good conditions for their larvae. Females indeed do that when laying their first egg batches (Porter, 1981, cited in Wahlberg, 2002b). However, conditions may change, and changing to a new oviposition site after laying the first egg batch may be a precaution against environmental variation (cf. Petit et al., 2001). Despite their relative sedentariness, some females of $E$. aurinia migrate between habitat patches (Warren, 1994; Wahlberg et al., 2002b): in our study, a marked female moved $2300 \mathrm{~m}$ in June 2002 (unpublished data). Still, it might be relatively easy for a female to distinguish suitable egg-laying sites. Since the host plant does bloom in late summer, its young rosettes are relatively unapparent during the period when adults are flying and the searching females are more likely to encounter plants growing in high densities and short sward. Ovipositing at a suitable site, even if outside the natal patch, thus agrees with the most parsimonious model of female behaviour.

\section{Conservation implications}

All Euphydryas aurinia localities in Western Bohemia are on human-created seminatural meadows that are either traditionally managed, or relatively recently abandoned.

In Britain, E. aurinia inhabits traditionally used pastures with low stocking density (Barnett \& Warren, 1995; Asher et al., 2001). Wahlberg et al. (2002b) contrasted the "static" situation with "dynamic" situation in forest clearings in Finland. The Czech populations seem to be intermediate. Traditional management consisted of a combination of cattle grazing and mowing. Grazing promotes cushion-forming grasses and maintains the level of soil disturbance suitable for germination of Succisa pratensis. Mowing, on the other hand, promotes fast growing grasses and maintains a uniform sward. It also causes substantial larval mortality (Barnett \& Warren, 1995). A second cut in late-season ("aftermath") must be especially detrimental to exposed and vulnerable larval nests.

The contrasting effects of mowing and grazing allow us to infer that the populations in Western Bohemia have traditionally persisted in a semi-dynamic state. They suffered an increased mortality if mowing occurred at an inappropriate time, or if a site was mown twice a year. However, some sites were always grazed, and management varied between individual landholders and years. The resulting small-scale mosaic of diverse management presumably contributed to the long-term persistence of local populations.

What habitat management may mimic the traditional land use? In the short term, the species should be managed on the scale of the extant colonies. The occupied sites on hay meadows should be mown once a year and always in a mosaic-like manner, leaving uncut the nutrient-poor patches containing Nardus stricta and a high cover Succisa pratensis. (Hand-mowing these patches every few years should suffice to block succession.) The mowing should coincide with the beginning of adult flight, since it will expose rather then destroy the rosettes of the host plant without harming the larvae. Occupied pastures should not be overstocked, sown with fodder mixtures or fertilised. Cattle should be temporarily excluded from patches with a high cover of $S$. pratensis. The management of unoccupied $S$. pratensis sites in vicinity of extant localities should restore short-sward conditions with a high density of the plant. This may be achieved by a removal of plant biomass and subsequent maintenance of uneven and patchily disturbed sod (Bulman, 2002), by light cattle grazing in late summer, or by small-scale mechanical disturbance. The ultimate goal should be not only to preserve the butterfly on its extant sites, but also to increase the number of occupied sites via purposeful habitat restoration.

\section{CONCLUSION}

Comparisons of the composition of the surrounding vegetation and architecture of the host plants (Succisa pratensis) occupied and unoccupied by larval nests of Euphydryas aurinia revealed valuable insights into the habitat requirements of this endangered butterfly. Although this required collecting of relatively large amount of data and non-trivial analytical approaches, it allowed us to define, accurately, the conditions required by larvae of the butterfly. It is encouraging that the presence of such conditions, such as low sward, high host plant density and relative cover of a few accompanying species may be assessed quickly, independently of season and with little experience. This should substantially ease the assessment of habitat suitability for the species in future site management actions.

ACKNOWLEDGEMENTS. This research would not have been possible without the help of Jindřich Franz, Lepidoptera enthusiast from Rybničná near Bochov, who for decades monitored the few then-known populations and introduced us to the butterfly. Many thanks to A. Pavličko, V. Holá, P. Holý and V. Šmicová for help in field, to $\mathrm{K}$. Boublik for assisting with plant identification, and to M. Malcová and M. Duchoslav for an electronic database of Ellenberg's values. J. Beneš, Š. Janeček and N. Wahlberg read the text and contributed valuable suggestions. Critical comments of P. Šmilauer and one anonymous referee substantially improved the quality of the paper. The study was funded by a Czech Ministry of Environment grant to Sagittaria foundation.

\section{REFERENCES}

Asher J., Warren M., Fox R., Harding P. \& JefFcoate G. (eds) 2001: The Millennium Atlas of Butterflies in Britain and Ireland. Oxford University Press, Oxford, $433 \mathrm{pp}$.

BARNETT L.K. \& WARREN M.S. 1995: Marsh Fritillary Eurodryas Aurinia. Species Action Plan. Butterfly Conservation, Wareham, Dorset. Unpublished technical report.

BeRgMAN K.O. 1996: Oviposition, host plant choice and survival of a grass feeding butterfly, the Woodland Brown (Lopinga achine) (Nymphalidae: Satyrinae). J. Res. Lepid. 35: 9-21.

BouRn N.A.D \& Thomas J.A. 1993: The ecology and conservation of the Brown Argus butterfly Aricia agestis in Britain. Biol. Conserv. 63 : 67-74.

BuHler C. \& SCHMID B. 2001: The influence of management regime and altitude on the population structure of Succisa 
pratensis: implications for vegetation monitoring $J$. Appl. Ecol. 38: 689-698.

Bulman C.R. 2002: Metapopulations and extinction: applying theory to conservation in fragmented landscapes. In: Pullin A.S. \& Warren M. (eds): Landscape and Lepidoptera Conservation. Butterfly Conservation 4th International Symposium. Proceedings of the conference held in Lancaster, England, in 5-8 September 2002, p. 4.

Descimon H., Zimmermann M., Cosson E., Barascud B. \& Neve G. 2001: Genetic variation, geographic variation and gene flow in some French butterfly species. Genet. Sel. Evol. 33 S223-S249, Suppl. 12001

Ehrlich P.R., White R.R., Singer M.C., McKechnie S.W., GilBERT L.E. 1975: Checkerspot butterflies: a historical perspective. Science 188: 221-228.

ElleNBERG H. 1979: Zeigerwerte der Gefässpflanzen Mitteleuropas. Scr. Geobot., Göttingen 9: 1-122.

FrANK D. \& KLOTZ S. 1990: Biologisch-ökologische Daten zur Flora der DDR. Wiss. Beitr. Martin-Luther-Univ., HalleWittenberg 32: 1-167.

Gutierrez D., Thomas C.D. \& Leon-Cortes J.L. 1999: Dispersal, distribution, patch network and metapopulation dynamics of the dingy skipper butterfly (Erynnis tages). Oecologia 121: 506-517

Hanski I. 1999: Metapopulation Ecology. Oxford University Press, Oxford, $308 \mathrm{pp}$.

HANSKi I. \& Singer M.C. 2001: Extinction-colonization dynamics and host-plant choice in butterfly metapopulations. Amer. Nat. 158: 341-353.

HưA V., KonvičKa M. \& Fric Z. (in press) Hnědásek chrastavcový (Euphydryas aurinia). In: Beneš J., Konvička M., Dvořák J., Fric Z., Havelda Z., Pavličko A., Vrabec V. \& Weidenhoffer Z.(eds): Butterflies of the Czech Republic: Distribution and Conservation I, II. SOM, Praha, pp. 468-473.

Kopper B.J, Charlton R.E. \& Margolies D.C. 2000: Oviposition site selection by the regal fritillary, Speyeria idalia, as affected by proximity of violet host plants. J. Insect Behow. 13: $651-665$.

Kotorova I. \& Leps J. 1999: Comparative ecology of seedling recruitment in an oligotrophic wet meadow. J. Veg. Science 10: $175-186$.

Krenova Z. \& LePs J. 1996: Regeneration of a Gentiana pneumonanthe population in an oligotrophic wet meadow. J. Veg. Science 7: 107-112.

LEPS J. 1999: Nutrient status, disturbance and competition: an experimental test of relationships in a wet meadow copy. $J$. Veg. Science 10: 219-230.

LEWIS O.T. \& HurFord C. 1997: Assessing the status of the marsh fritillary butterfly (Eurodryas aurinia): An example from Glamorgan, UK. J. Insect Conserv. 1: 159-166.

MAŠEK J. 1987: Notes on ecology of Euphydryas aurinia Rott. (Lepidoptera: Nymphalidae). Zprávy Muzea Západočeského Kraje - Přrroda (Plzeň) 34-35: 53-54. [in Czech]

Munguira M.L., Martín C., García-Barros E. \& Viejo J.L. 1997: Use of space and resources in a Mediterranean population of the butterfly Euphydryas aurinia. Acta Oecol. 18: $597-612$.

Murrety D.D. \& WeIss S.B. 1988: Ecological studies and the conservation of the bay checkerspot butterfly, Euphydryas editha bayensis. Biol. Conserv. 46: 183-200.

OSBORNE K.H. \& REDAK R.A. 2000: Microhabitat conditions associated with the distribution of postdiapause larvae of Euphydryas editha quino (Lepidoptera: Nymphalidae). Ann. Entomol. Soc. Am. 93: 110-114.
Pauli D., Peintinger M. \& Schmid B. 2002: Nutrient enrichment in calcareous fens: effects on plant species and community structure. Basic Appl. Ecol. 3: 255-266.

Petit S., Mollanen A., Hanski I. \& Baguette M. 2001: Metapopulation dynamics of the bog fritillary butterfly: movements between habitat patches. Oikos 92: 491-500

PORTER K. 1982: Basking behaviour in larvae of the butterfly Euphydryas aurinia. Oikos 38: 308-312.

PoRTER K. 1984: Sunshine, sex-ratio and behaviour of the Euphydryas aurinia larvae. In: Vane-Wright H.T. \& Ackery P.R. (eds): The Biology of Butterflies: Symposium of the Royal Entomological Society of London. Academic Press, London, pp. 309-315.

SChaffers A.P. \& SYKora K.V. 2000: Reliability of Ellenberg indicator values for moisture, nitrogen and soil reaction: a comparison with field measurements. J. Veg. Science 11: 225-244.

SINGER M.C. 1983: Determinants of multiple host use by a phytophagous insect population. Evolution 37: 398-403.

Singer M.C. \& PARMESAN C. 1993: Sources of variation in patterns of plant-insect association. Nature 361: 251-253.

Singer M.C., Stefanescu C. \& Pen I. 2002: When random sampling does not work: Standard design falsely indicates maladaptive host preferences in a butterfly. Ecol. Lett. 5: 1-6.

Sparks T.H., Porter K., Greatorex-Davies J.N., Hall M.L. \& MARRS R.H. 1994: The choice of oviposition sites in woodland by the Duke of Burgundy butterfly Hamearis lucina in England. Biol. Conserv. 70: 257-264.

S-Puus 2000. 1999: Guide to statistics, Volume 1. Data Analysis Products Division, MathSoft, Seattle, WA, $637 \mathrm{pp}$.

ŠTEÉPANEK J. \& HOLUBB J. 1997: Succisa Haller - čertkus. In: Slavík B. (ed.): Flora of the Czech Republic 5. Academia, Praha, pp. 542-543.

TER BraAk C.J.F. \& ŠMilauer P. 2002: CANOCO Reference Manual and User's Guide to Canoco for Windows: Software for Canonical Community Ordination (version 4.52). Microcomputer Power (Ithaca, NY USA), 500 pp.

Thomas J.A., Bourn N.A.D., Clarke R.T., Stewart K.E., Smcox D.J., Pearman G.S., Curtis R. \& Goodger B. 2001: The quality and isolation of habitat patches both determine where butterflies persist in fragmented landscapes. Proc. $R$. Soc. London (B) 268: 1791-1796.

Thomas J.A. \& Simcox D. 1982: A quick method for estimating larval populations of Melitaea cinxia L. during surveys. Biol. Conserv. 22: 315-322.

VAN SwaAy C.A.M. \& WaRREN M.S. 1999: Red Data Book of European Butterflies (Rhopalocera). Nature and Environment Series No. 99, Council of Europe, Strasbourg, 260 pp.

WAHLBERG N. 2000: Comparative descriptions of the immature stages and ecology of five Finnish melitaeine butterfly species (Lepidoptera: Nymphalidae). Entomol. Fennica 11: 167-174.

Wahlberg N., Mollanen A. \& Hanski I. 1996: Predicting the occurrence of endangered species in fragmented landscapes. Science 273: 1536-1538.

Wahlberg N., Klemetti T., Selonen V. \& Hanski I. 2002a: Metapopulation structure and movements in five species of checkerspot butterflies. Oecologia 130: 33-43.

Wahlberg N., Klemetti T. \& Hanski I. 2002b: Dynamic populations in a dynamic landscape: the metapopulation of the marsh fritillary butterfly. Ecography 25: 224-232.

Wamelink G.W.W., Joosten V., Van Dobben H.F. \& Berendse F. 2002: Validity of Ellenberg indicator values judged from physico-chemical field measurements. J. Veg. Sc. 13: 269-278. 
WARREN M.S. 1987: The ecology and conservation of the heath fritillary, Mellicta athalia. I. Host selection and phenology. $J$. Appl. Ecol. 24: 467-482.

WARREN M.S. 1994: The UK status and suspected metapopulation structure of a threatened european butterfly, the Marsh Fritillary Eurodryas aurinia. Biol. Conserv. 67: 239-249.
Weiss S.B., MuRPhy D.D. \& White R.R. 1988: Sun, slope and butterflies: topographic determinants of habitat quality for Euphydryas editha. Ecology 69: 1486-1496.

WhITE R.R. 1974: Food plant defoliation and larval starvation of Euphydryas editha. Oecologia 14: 307-315.

Received January 20, 2003; revised April 28, 2003; accepted May 19, 2003 